\title{
SYSTEM TO CONTROL INDOOR AIR QUALITY IN ENERGY EFFICIENT BUILDINGS
}

G.G.Mandayo $^{1}$,J.Gonzalez-Chavarri ${ }^{1}$, E.Hammes ${ }^{2}$, H.Newton ${ }^{3}$, I.Castro-Hurtado ${ }^{1}$, H.Knapp ${ }^{2}$, A. Sweetman ${ }^{3}$, C.N. Hewitt ${ }^{3}$, E.Castaño ${ }^{1}$

${ }^{1}$ Ceit and Tecnun (Universidad de Navarra),P.Mikeletegi 48, 20009 San Sebastián, Spain;

${ }^{2}$ CSEM Alpnach, Untere Gründlistrasse 1,CH-6055 Alpnach Dorf, Switzerland;

${ }^{3}$ Lancaster Environment Centre, Lancaster University, Lancaster, LA1 4YQ, United Kingdom

e-mail addresses: ggmandayo@ceit.es;.jgchavarri@ceit.es; emily.hammes@csem.ch;

h.newton@lancaster.ac.uk; ichurtado@ceit.es; helmut.knapp@csem.ch;

a.sweetman@lancaster.ac.uk; n.hewitt@lancaster.ac.uk; ecastano@ceit.es

postal address of corresponding author: Paseo Mikeletegi 48,20009 Donostia-San Sebastian, Spain, Tel. +34943212800 (Ext. 2905), Fax: +34 943213076

\begin{abstract}
This work aims at monitoring air quality in indoor environments through the integration of several sensing technologies into a single robust, reliable and cheap detection platform, which shares air pre-conditioning and electronics. Target gases and detection limits have been set according to recommendations of different agencies in Europe and the US. The system has reached detection limits stated by the OSHA (Occupational Safety and Health Administration) for benzene. The pre-conditioning fluidic platform has also been designed, simulated, fabricated and tested with sensors so the gas flow has been optimized. Field tests in real buildings are being carried out to contrast current measurement procedures and results with the obtained using the device under development. The main aim of the system is to control HVAC (Heat Ventilation and Air Conditioning) in energy-efficient way while keeping a high air quality standard inside the building.
\end{abstract}

\section{Highlights}

A system to control indoor air quality is being designed, fabricated and tested.

Conductometric sensors based on nanostructured $\mathrm{ZnO}$ are developed for the system.

A fluidic unit is being developed to improve the performance of the sensors.

Field studies in buildings are carried out to be contrasted with the developed system.

\section{Key words}

Indoor air quality, air preconditioning unit, fluidic platform, gas conductometric sensor, benzene, zinc oxide.

\section{Introduction}

Minimizing heating and cooling requirements is crucial to improve a building's energy efficiency. Therefore, most energy efficient climate control systems minimize the fresh air going into the building by recirculating most of the air. However, this can reduce air quality $[1,2]$, which has become a public health concern in many countries.

The World Health Organization (WHO) [3] recognized indoor-air pollution is the 8th most important factor for health and responsible for $2.7 \%$ of the global burden of diseases. Indoor air quality (IAQ) has become an important issue since the development of double glazing in the 1970's and buildings becoming increasingly energy efficient and thus better sealed: the concentration of contaminants may build up in an enclosed space and so the risks to health may be greater. This fact is particularly significant because Europeans spend on average 80$90 \%$ of their time indoors [4,5]. Volatile Organic Compounds (VOCs) and inorganic gases 
can contribute to poor IAQ and have been linked to symptoms of Sick Building Syndrome: an ambiguous term describing a wide range of symptoms related to a particular building [6].

Benzene is one of the 20 most relevant toxic chemicals produced in the US. It is a VOC used in the manufacturing of petroleum-derived products such as plastics, resins, nylon and synthetic-fibre manufacturing, among others. It also comes from some natural sources, such as volcanic emissions and wildfires, and it is closely related to some human activities such as tobacco consumption or gasoline combustion. Regarding its health effect, it is carcinogenic (according to the WHO) [7] and it may also be the cause of other diseases such as plastic anaemia, acute leukaemia, and bone marrow abnormalities (according to the Agency for Toxic Substances and Disease Registry-ATSDR) [8]. As a reference, the OSHA states a STEL (Short Term Exposure Limit) of $5 \mathrm{ppm}$ and an action level of $500 \mathrm{ppb}$. According to the results of the INDEX EU project on indoor air quality assessment [9], it is one of the five indoor-originated compounds considered the most hazardous.

As many organisations and nations are now recognising the need to balance ventilation, energy efficiency and IAQ [10,11], the main objective of this work is to provide a low-cost and high-sensitivity integrated device to measure IAQ that can be either used as an independent monitoring system or can be linked to the HVAC system. This aim will be achieved through the integration of different sensing technologies onto a common detection platform. The system comprises technological developments: conductometric sensors for volatile organic compound (VOC) detection, and a fluidic preconditioning and handling system, as a platform for all the sensing elements, the developed within this work for gas detection and the commercial ones for humidity and temperature monitoring.

\section{System description and experimental}

The system consists on a common platform with some shared capabilities to supply the air to the gas sensors. The multisensor platform (Figure 1) has been designed by CSEM to deliver equal quantities of ambient air to three sensor chambers simultaneously. The fluid transport through the system was modelled prior to construction using COMSOL Multiphysics ${ }^{\circledR}$. The material has been chosen to be compatible with the working conditions of the sensors, particularly with the high temperature the conductometric sensors can reach. The system contains a pump, a temperature and humidity sensor to calibrate the conditions of the air intake, and filters to control the humidity levels of the air reaching the sensors. As can be seen in Figure 1, air enters the device at the far left, where it is filtered and the temperature and humidity are measured before the gas path trifurcates. Gas is then delivered to three sensor chambers in parallel. Then the flow rate is measured before being sucked into the pump and out of the device.

In order to check the uniformity of the air flow, the design was verified using e2V EC410 oxygen sensors, which were placed in the sensor chambers. For that purpose, the inlet gas was allowed to fluctuate between ambient air and air with reduced levels of oxygen. 


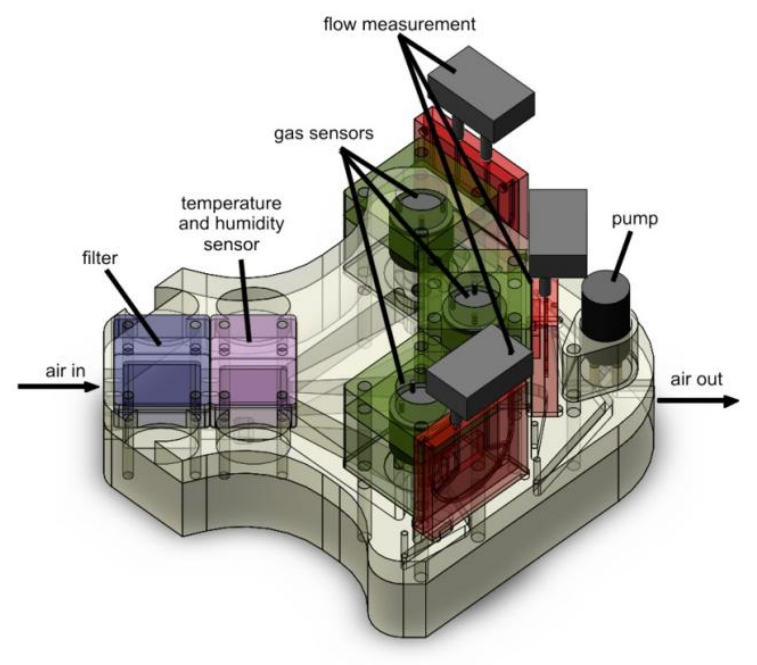

Figure 1. Image of the three sensor housing unit

Conductometric sensors based on metal oxide semiconductors $\left(\mathrm{ZnO}, \mathrm{SnO}_{2}\right.$ and $\left.\mathrm{NiO}\right)$ are being developed by the Microsystems and Microelectronics group at CEIT for this platform. This technology has been chosen because it is one of the most suitable for mass production. The final prototype will contain 3 different conductometric sensors. In this context, fabrication methods for $\mathrm{SnO}_{2}[12,13]$, and $\mathrm{NiO}[14,15]$ thin films were previously developed as well as methods for $\mathrm{SnO}_{2}$ nanowire fabrication [16]. It is commonly agreed that onedimensional nanostructures of those metal oxides, such as nanowires and nanorods, usually constitute improved sensing structures because sensitivity and velocity of response are closely related to the surface activity of the material. At the moment a fabrication process for the insitu manufacturing of $\mathrm{ZnO}$ nanostructures is being investigated [17]. To that end, Vapour Liquid Solid (VLS) technique [18] is used to grow nanostructures precisely over Pt electrodes, as shown in Figure 2. First, Pt electrodes are grown on the alumina substrate by DC sputtering through a lift-off process (steps 1 to 3 in Figure 2), secondly, $\mathrm{Zn}$ is also deposited by sputtering onto the electrodes (steps 4 and 5 in Figure 3), and finally the VLS process is carried out in nitrogen and oxygen controlled flow at high temperature.

1)

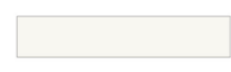

4)

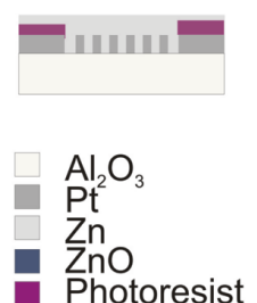

2)

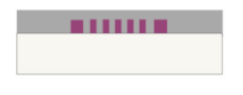

5)

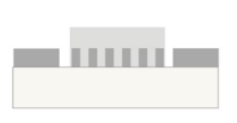

$6)$

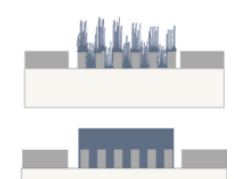

Figure 2. Steps for sensor fabrication

The sensor prototype has been designed and fabricated on an alumina substrate with an integrated Pt heater, whose performance has been characterized through a thermography IR 
camera FLIR-P25. The sensor prototype has been measured in two different packages and power comsumptions of the two packaging conditions is compared.

The characterization of the sensors' signal in the lab environment is performed inside sealed chambers under a fixed flow. The target atmosphere of benzene is obtained by means of a mixing system consisting of mass flow controllers (MFCs) from Bronkhorst Hi-Tech controlled by a PC. A Dynamic Data Exchange communication is established between the computer and the MFCs to operate them by Labview@ (Figure 3).

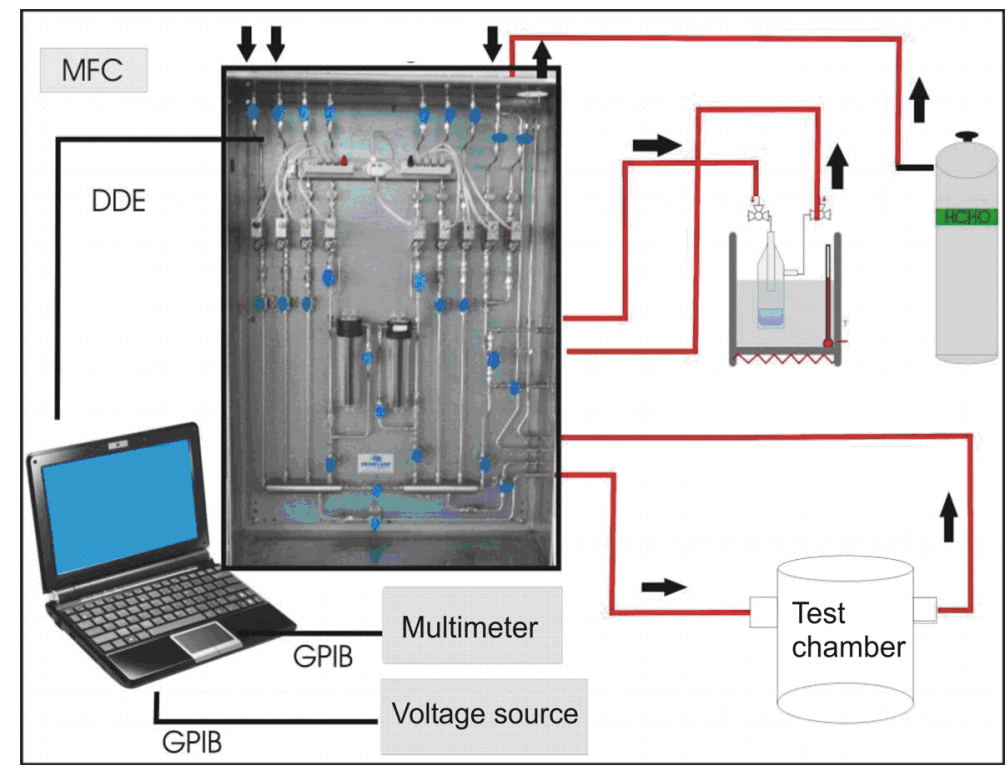

Figure 3. Setup for gas sensor test: gas mixing and data acquisition systems

In order to compare the results of the developed sensor with the obtained by currently used methods, an active sampling of VOCs in a modern university building is being carried out. In particular, air samples were taken throughout the new Lancaster Institute for the Creative Arts (LICA) building (built 2010) at Lancaster University. The LICA building is non-residential, including offices, dance studios, seminar rooms and study areas. The building utilises a passive ventilation system. The data presented here in this paper are from a preliminary characterisation of the IAQ within LICA. Active air sampling was conducted using pocket pumps attached to Markes sorbent tubes, 6 litres of sample air was drawn through each tubes for analysis by Thermal Desorption- Gas Chromatography- Mass Spectrometry (TD-GC-MS) using a Perkin Elmer system. The GC-MS was calibrated using a Supelco BTEX standard containing benzene, toluene, ethylbenzene and xylenes.

\section{Results and discussion}

First, the results related to the support platform will be analyzed, secondly the results of the measurements with the conductometric $\mathrm{ZnO}$ sensors will be shown, and finally, the test fields performed in a real building will be described and analyzed.

\subsection{Pre-conditioning fluidic platform performance}

The first aim of the support platform is to manage the flow reaching the gas sensors, so that it is uniform. Secondly, it has to keep the humidity at known levels and finally it must be an interface between the sensors and the signal conditioning and control electronic board (which is out of the scope of this communication). At this stage, tests to verify the uniformity of the flow within the sensors have been carried out. 
The results of the test performed in the fluidic platform show identical response times, indicating that the gases arrive at the sensor simultaneously, and similar peak heights, indicating that the amount of gas flowing through the device is comparable (Figure 4). Flow rates were also monitored, confirming this point. The sensor chamber itself is not limited by the sensor operation method, and has currently been tested with both metal oxide sensors and chemical sensors with sensor housings with diameters which range from $7 \mathrm{~mm}$ to $17 \mathrm{~mm}$.

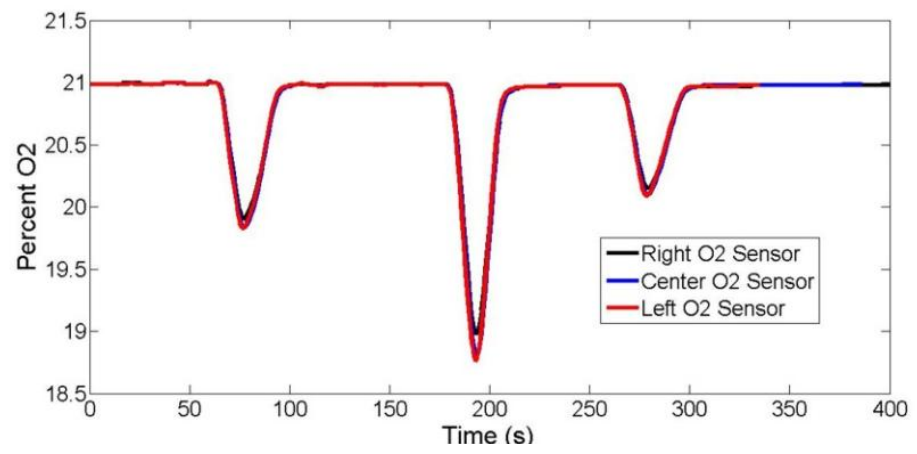

Figure 4. Response the three oxygen sensors in the three chambers

\subsection{Conductometric $\mathrm{ZnO}$ sensor}

The results of the characterization of a sensor prototype are explained in the following paragraphs. All the three sensors will have the same package, same sensor die, but the sensing material will be different.

The sensor layout consists of a Pt heater surrounding the sensing material, so all the sensor is fabricated on the same side of the alumina substrate, with a whole size of $2.5 \times 2.5$ square millimetres (Figure 5, left). After optimizing the fabrication parameters, the sensors were fabricated and were packaged in two different TO holders to compare their performance. In the first case, the sensor was suspended in the air and in the second case it was glued to the holder, as the one in the right hand side of Figure 5.
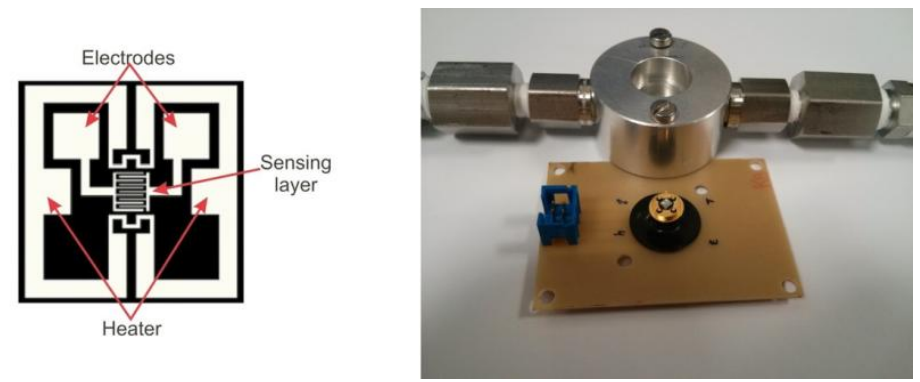

Figure 5. Sensor prototype scheme (left), and packaged sensor on test board (right)

In order to test the heat distribution on the surface of the sensors, the integrated heater was supplied with increasing power to check the sensor surface temperature, which was measured using an IR thermography camera. The results show that in terms of power consumption, the glued sensor requires three times more power than the suspended one (Figure 6), but the glued sensor is more robust to be handled. As in both cases the power consumption of the sensor compared to other elements in the system is low, any of the two would be suitable for the system. The temperature distribution was also simulated using ANSYS and the temperature distribution found was in good agreement with the measurements with the IR thermography 
camera. The most important fact is that the sensing area is held at uniform temperature with the designed heater.

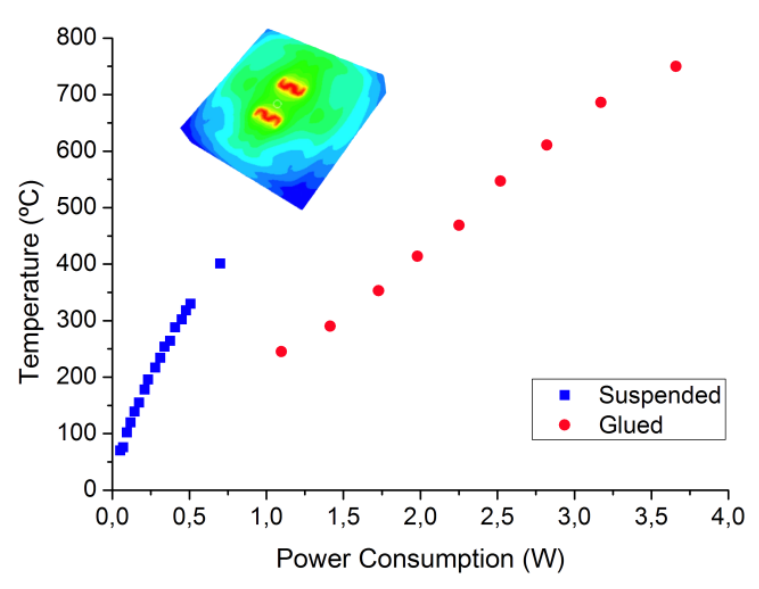

Figure 6. Power consumption of the glued and suspended sensor and simulation of the temperature distribution

The $\mathrm{ZnO}$ sensor response (resistance change) to benzene was measured in a controlled atmosphere of benzene in air, under a sequence of pulses of 30 minutes of benzene followed by 30 minutes in clean air. The sequence started with $20 \mathrm{ppm}$ of benzene followed by decreasing concentrations down to $500 \mathrm{ppb}$. The sensor shows a good recovery of the baseline after each pulse, and an average time of response of $2 \mathrm{~min}$, as can be seen in Figure 7. The sensitivity of the sensor within this range is $2 \%$ per ppm (Figure 8). If the sensor response is compared with other authors who reached similar benzene low concentrations with conductometric sensors, in the case of the $\mathrm{SnO}_{2}$ sensor in [21], the response to $500 \mathrm{ppb}$ of benzene is below $1 \%$, while in the current device is $2 \%$. Moreover, the drift in the sensor baseline is higher than the presented here, and in the order of the response to $500 \mathrm{ppb}$ of benzene. Such low levels of benzene are usually not reported using bare metal oxide conductometric sensors, and the literature reports the need of pre-concentrating elements for them [Error! Reference source not found.].

If the sensor is compared with other sensors of the same technology currently in the market, the TGS 822 of Figaro [20], for organic solvent vapours, only shows results for concentrations of benzene down to $50 \mathrm{ppm}$, which is still far from the $5 \mathrm{ppm}$ STEL requested by the OSHA standards. 


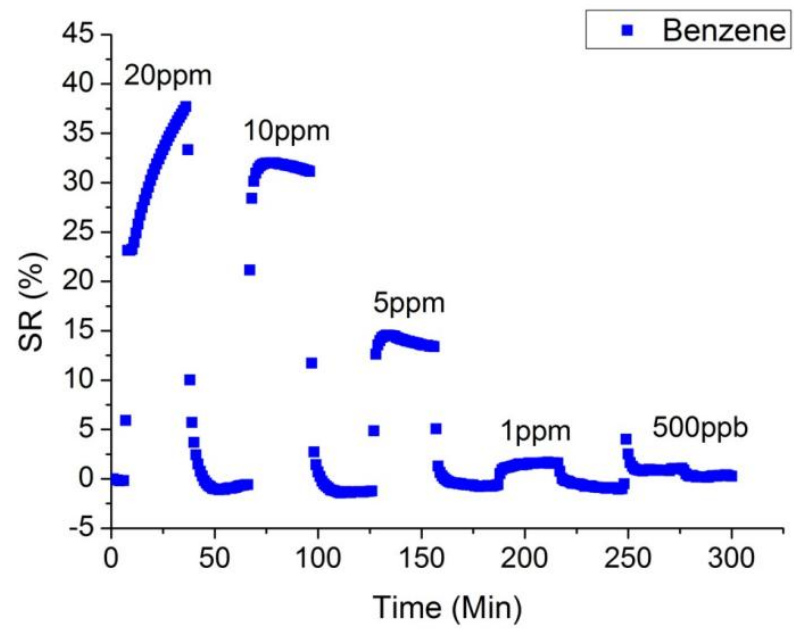

Figure 7. $\mathrm{ZnO}$ sensor response to benzene concentrations from $20 \mathrm{ppm}$ to $500 \mathrm{ppb}$ at $250^{\circ} \mathrm{C}$

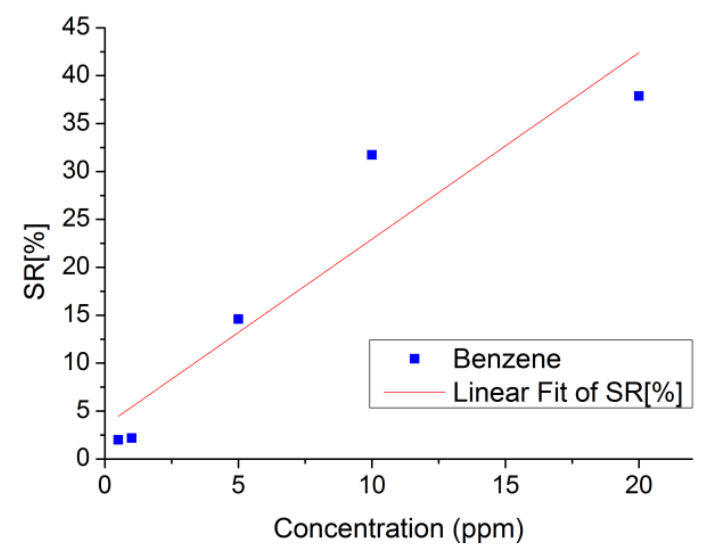

Figure 8 . Sensitivity curve of the $\mathrm{ZnO}$ sensor in the $20 \mathrm{ppm}-500 \mathrm{ppb}$ range at $250^{\circ} \mathrm{C}$

It can be stated that the detection level reached by the sensor exceeds the devices of the same technology available in the market. Another disadvantage of the currently available sensors, also in the TGS 822 of Figaro is cross-sensitivity to humidity, which will be avoided in this system by means of filters included in the pre-conditioning fluidic platform.

\subsection{Real field measurements}

The sampling in real buildings took place in May and June of 2013 throughout the different types of rooms within LICA, with triplicate measurements at each of the 8 locations. Mean concentrations from all room types in LICA can be seen in Table 1.

\begin{tabular}{lllll} 
& Benzene & Ethylbenzene & Toluene & Xylenes $(\mathrm{m}-, \mathrm{o}-, \mathrm{p}-)$ \\
\hline $14 / 05 / 2013$ & - & $5 \mathrm{ppb}$ & $1 \mathrm{ppb}$ & $3 \mathrm{ppb}$ \\
& & $1 \mathrm{ppb}$ & $1 \mathrm{ppb}$ & $0.1 \mathrm{ppb}$
\end{tabular}

Table 1. Mean concentrations seen in Lancaster University's LICA building during May and June 2013. 
Measurements are continuing in the same locations within LICA to further understand the variation between the two sampling dates. Despite the variation between sampling dates the concentrations remain below recommended guidelines set by OSHA, NIOSH (National Institute for Occupational Safety and Health) and ASTDR (Agency for Toxic Substances and Disease Registry). This pilot study of LICA validated the sampling volumes and method for this application. Intra-annual variation will be investigated to ascertain how season and academic terms impact on the IAQ in LICA. LICA will be compared to other modern buildings on campus with different ventilation systems as well as a comparison with the older non-residential buildings on campus.

The method used for the field measurements shows detection levels far below the ones reached by the developed sensor, but these measurements are time consuming, and require very costly and bulky equipments that make it not useful for IAQ on-line measurements. The final aim of the current development is to develop a low-cost product to be bought in the consumer market to ensure a minimum air quality in buildings. The results shown are on the right way to reach this goal.

\section{Conclusions}

Some critical parts of the air quality measuring system have been analyzed. In the microfluidic platform, all the required elements have been integrated (pump, filters, and temperature and humidity sensor) and the uniformity of the flow reaching the three sensor chambers has been verified using commercial sensors.

Regarding the sensors, a conductometric sensor prototype has been developed, which can be used to implement different metal oxides on it. Its temperature and power consumption has been analyzed and both are suitable for the fluidic platform. A $\mathrm{ZnO}$ nanostructured layer has been tested in the prototype, and compared with other sensors in the market and in other research groups, showing lower detection limit if compared with the commercial sensor and less drift and higher response when compared to other research.

Finally, the suitability of active air sampling through pocket pumps attached to Markes sorbent tubes and subsequent TD-GC-MS analysis has been validated as a suitable method to detect very low concentrations of benzene, among other BTEX compounds.

This method has been compared to the sensor developed, reaching the conclusion that the application fields are not the same. While the described field analysis is very suitable for accurate measurements, it requires bulky equipment and skilled personnel to be carried out, as a long lengthy sampling and analysis time. Moreover, the cost of this system analytical technique would be at least one thousand times bigger than the expected for the system described here.

\section{Aknowledgements}

Funding for this work was provided by the European Union through the INTASENSE project, grant no. 285037 "Integrated air quality sensor for energy efficient environment control" under the program EeB.ENV.2011.3.1.5-1 "Technologies for ensuring, monitoring and/or controlling a high quality indoor environment, particularly in relation to energy efficient buildings". Thanks to Mengqian Liu for collecting the LICA samples at Lancaster University.

\section{References}

1. W.J. Fisk, A.G. Mirer and M.J. Mendell, Quantitative relationship of sick building syndrome symptoms with ventilation rates, Indoor Air 19(2) (2009) 159-165.

2. J. Sundell, H. Levin, W.W. Nazaroff, W.S. Cain, W.J. Fisk, D.T. Grimsrud, F. Gyntelberg, Y. Li, A.K. Persily, A.C. Pickering, J.M. Samet, J.D. Spengler, S.T. 
Taylor and C.J. Weschler, Ventilation rates and health: multidisciplinary review of the scientific literature, Indoor Air 21(3) (2011) 191-204.

3. WHO, Air quality guidelines. Global update 2005, The WHO European Centre for Environment and Health, Bonn Office, World Health Organization: 484 (2006)

4. Y. Bruinen de Bruin, K. Koistinen, S. Kephalopoulos, O. Geiss, S. Tirendi and D. Kotzias, Characterisation of urban inhalation exposures to benzene, formaldehyde and acetaldehyde in the European Union, Environ. Sci. Pollut. R. 15(5) (2008) 417-430.

5. D.A. Sarigiannis, S.P. Karakitsios, A. Gotti, I.L. Liakos and A. Katsoyiannis, Exposure to major volatile organic compounds and carbonyls in European indoor environments and associated health risk, Environ. Int. 37(4) (2011) 743-765.

6. C. A., Redlich, J. Sparer and M.R. Cullen, Sick-building syndrome, The Lancet 349(9057) (1997) 1013-1016.

7. WHO guidelines for indoor air quality: selected pollutants, ISBN 978928900213 4, (C) World Health Organization 2010.

8. ATSDR Publication No.: ATSDR-HE-CS-2001-0003, Case Studies in Environmental Medicine: Benzene toxicity, www.atsdr.cdc.gov/csem/benzene/docs/benzene.pdf (Accessed 2013-11-29).

9. K. Koistinen, D. Kotzias, S. Kephalopoulos, C. Schlitt, P. Carrer, M. Jantunen, S. Kirchner, J. McLaughlin, L. Mølhave, E. O. Fernandes, B. Seifert, The INDEX project: executive summary of a European Union project on indoor air pollutants, Allergy 2008: 63 (2008) 810-819.

10. E.E. Agency, Every breath we take: Improving air quality in Europe. EEA SIGNALS 2013. Luxembourg: Publications Office of the European Union, European Environment Agency (2013).

11. K. W. Tham, Priorities for ISIAQ in addressing climate change and sustainability challenges, Indoor Air 23(1) (2013) 1-3.

12. G.G. Mandayo, E. Castaño, F.J. Gracia, A. Cirera, A. Cornet, J.R. Morante, Strategies to enhance the carbon monoxide sensitivity of tin oxide thin films, Sensor. Actuat. BChem. 95 (2003) 90-96.

13. G. $\mathrm{G}^{\mathrm{a}}$ Mandayo, Gas detection by semiconductor ceramics: tin oxide as improved sensing material, Sensors Letters Vol.5, no 2, (2007) 341-360.

14. I. Castro-Hurtado, J. Herrán, N. Pérez, S.M. Olaizola, G. Ga Mandayo, E. Castaño, Toxic gases detection by NiO sputtered thin films, Sensors Letters vol.9 (2011) 1-5.

15. I. Castro-Hurtado, J. Herrán, G. G ${ }^{a}$ Mandayo, E. Castaño, "Studies of influence of structural properties and thickness of $\mathrm{NiO}$ thin films on formaldehyde detection", Thin Solid Films 520 (2011) 947-952.

16. I. Castro-Hurtado, J. Herrán, G. Ga Mandayo, E. Castaño, " $\mathrm{SnO}_{2}$-nanowires grown by catalytic oxidation of tin sputtered thin films for formaldehyde", Thin Solid Films 520 (2012) 4792-4796.

17. J. Gonzalez-Chavarri, I. Castro-Hurtado, G.G. Mandayo, E. Castaño, "Straightforward $\mathrm{ZnO}$ nanostructures fabrication for the measurement of toxic gases", EUROMAT Conference, Sevilla, Spain (2013)

18. E. Comini, C. Baratto, G. Faglia, M. Ferroni, A. Vomiero, G. Sberveglieri, Quasi-one dimensional metal oxide semiconductors: Preparation, characterization and application as chemical sensors, Prog. Mater. Sci. 54 (2009) 1.

19. B. Ghaddab, F. Berger, J.B. Sanchez, P. Menini, C. Mavon, P. Yoboue, V. Potin, "Benzene monitoring by micro-machined sensors with $\mathrm{SnO} 2$ layer obtained by using micro-droplet deposition technique", Sensor. Actuat. B-Chem. 152 (2011) 68-72

20. http://www.figarosensor.com/products/822pdf.pdf (Accessed 2013-11-29) 
21. B. Ghaddab, F. Berger, J.B. Sanchez, P. Menini, C. Mavon, P. Yoboue, V. Potin, Benzene monitoring by micro-machined sensors with $\mathrm{SnO} 2$ layer obtained by using micro-droplet deposition technique, Sensor. Actuat. B-Chem. 152 (2011) 68-72

22. H. Lahlou, X. Vilanova, X. Correig, Gas phase micro-preconcentrators for benzene monitoring: A review, Sensor. Actuat. B-Chem. 176 (2013) 198- 210 